\title{
Home blood pressure is the predictor of subclinical target organ damage like ambulatory blood pressure monitoring in untreated hypertensive patients
}

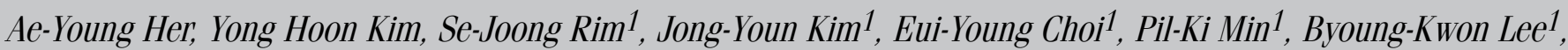 \\ Bum-Kee Hong ${ }^{1}$, Hyuck Moon Kwon ${ }^{1}$
}

Division of Cardiology, Department of Internal Medicine, School of Medicine, Kangwon National University; Chuncheon-Republic of Korea 1Division of Cardiology, Gangnam Severance Hospital, Yonsei University College of Medicine; Seoul-Republic of Korea

\section{ABSTRACT}

Objective: Home blood pressure (HBP) measurements are known as an important adjunct to office blood pressure (OBP) measurements in clinical practice. But little is known about the relationship between HBP and subclinical target organ damage (TOD) other than left ventricular hypertrophy (LVH). So we investigated the relationship of HBP measurements with subclinical TOD in untreated hypertensive patients.

Methods: We measured ambulatory blood pressure (ABP), HBP and OBP of 93 untreated hypertensive patients (men: 60 and women: 33 , mean age, $49 \pm 13$ years). The ABP was recorded for 24 hours, HBP was measured for one week, and OBP was measured at least in two visits. All BP measurements were taken using automatic BP measuring device. The parameters indicating subclinical TOD were the left-ventricular mass index (LVMI) by transthoracic echocardiography, urinary albumin excretion rate (AER), brachial ankle pulse-wave velocity (PWV), and carotid intima-media thickness (IMT).

Results: The LVMI was significantly correlated with systolic HBP and 24 hours systolic ABP, but not with OBP. The AER, PWV and IMT were also significantly correlated with systolic HBP and 24 hours systolic ABP. In a binary logistic regression analysis, systolic HBP, 24 hours systolic and diastolic ABP were the predictors of LVMI, AER and PWV (all $p<0.05$ ).

Conclusion: Our data suggest that HBP is as good as ABP monitoring and superior to OBP measurements in regard to their association with subclinical TOD. Therefore, HBP measurements give valuable information on the subclinical TOD in hypertensive patients in addition to ABP monitoring. (Anadolu Kardiyol Derg 2014; 14: 711-8)

Key words: home blood pressure, ambulatory blood pressure, target organ damage

\section{Introduction}

Hypertension is a strong, independent risk factor for cardiovascular disease (1). Generally, the diagnosis of hypertension is based on the traditional method of taking auscultatory measurements (office blood pressure, OBP) in a clinical setting. However, because of the white-coat and the masked hypertensive phenomena, OBP may be unrepresentative of the true blood pressure in about $30 \%$ of the patients who visit hypertension clinics (2). Actually current guidelines and recommendations suggest that diagnosis and treatment of hypertension should no longer be based on OBP alone, and that incorporation of out-of-office measurements should be mandatory $(3,4)$.

Previous studies showed that ambulatory blood pressure (ABP) and home blood pressure (HBP) measurements are more reproducible than $\mathrm{OBP}$ measurements (5). $\mathrm{ABP}$ measurements are more closely related to subclinical target organ damage (TOD) $(6,7)$ and a risk of cardiovascular events $(8,9)$. Other reports also suggested that HBP is useful in predicting hypertension-induced TOD, and is superior to carefully taken OBP measurements (10).

However, although several studies have reported the association of HBP with indices of subclinical TOD, evidence of the value of HBP in predicting subclinical TOD is still limited (11). Little is known about the relationship between HBP and hypertensive subclinical TOD other than left ventricular hypertrophy (LVH). Apart from the studies of LVH, controversial results were present for assessing all the other TOD indices $(12,13)$. Therefore, we investigated the relationship of HBP measurements with all indices of subclinical TOD with a direct comparison versus OBP and $A B P$ measurements in untreated hypertensive patients.

Address for Correspondence: Dr. Se-Joong Rim, M.D., Ph.D. Division of Cardiology, Gangnam Severance Hospital, Yonsei University College of Medicine, Dogok 1-Dong, Gangnam-Gu, Seoul ,135-720-Korea Phone: (82-2)-2019-3336 Fax: (82-2)-3463-3882 E-mail: sejoong@yuhs.ac

Accepted Date: 03.12.2013 Available Online Date: 08.04.2014 


\section{Methods}

\section{Study population}

Untreated hypertensive patients aged 20 to 75 years with systolic $\mathrm{OBP} \geq 140 \mathrm{~mm} \mathrm{Hg}$ or diastolic $\mathrm{OBP} \geq 90 \mathrm{~mm} \mathrm{Hg}$ on two routine pre-study office visits were included. The patients had not received antihypertensive drug treatment for at least six months before joining the study. Patient exclusion criteria were systolic blood pressure (SBP) $>200 \mathrm{~mm} \mathrm{Hg}$ and/or diastolic blood pressure (DBP) $>120 \mathrm{~mm} \mathrm{Hg}$ anytime during the study and a history of secondary hypertension, congestive heart failure, coronary artery disease, valvular heart disease, serum creatinine $>1.5 \mathrm{mg} / \mathrm{dL}$, overt proteinuria or hematuria, and the use of any drug known to influence blood pressure within four weeks before and during the study. All patients gave informed consent for study participation and we had the Ethic Committee report.

\section{Blood pressure measurements}

Blood pressure was measured in the office, at home, and with ambulatory monitoring. OBP was measured by trained physicians in two study visits, one week apart, using a validated oscillometric device with memory capacity (bladder size, $23 \times 12 \mathrm{~cm}$ or $28 \times 14 \mathrm{~cm}$ where appropriate; Omron HEM-705CP; Omron Healthcare $\mathrm{GmbH}$, Hamburg, Germany). OBP measurements were performed at each visit after 5 min of sitting rest and with at least 1 min between recordings (14). HBP was self-monitored by patients who used the same device and cuff as for OBP measurements (Omron HEM705CP). The patients were trained and instructed to perform HBP measurements using the above mentioned device in duplicates, once in the morning (7:00-10:00 AM) and in the evening (6:00-9:00 PM), after 5 min of sitting rest and with 1 min between readings, for six routine working days within two weeks (4). All patients were under a 24 hour non-invasive ABP monitoring with a validated oscillometric device (Tonoport V, GE healthcare, USA). Blood pressure monitoring was performed on working days with patients performing usual daily activities and refraining from heavy physical exercise. Blood pressure and heart rate readings were obtained every $15 \mathrm{~min}$ during the day (7:00 AM-11:00 PM) and every 30 min during the night (11:00 PM-7:00 AM). Patients were instructed to keep a diary of their activities and note the time they retired to bed, and ABP recordings were subdivided accordingly into "awake" or "asleep" periods based on these diary entries, which practically coincided, in most patients, with arbitrarily defined day and night subperiods. Blood pressure variability (BPV) was calculated as the standard deviation (SD) of mean awake and asleep SBP and DBP (15). BPV over 24 hours was obtained from the weighted average of day and night blood pressure SD values (16).

\section{Measurement of subclinical TOD: Left-ventricular mass index}

The LVH becomes a preclinical disease and an independent risk factor for congestive heart failure, ischemic heart disease, arrhythmia, sudden death, and stroke (17). M-mode and two- dimensional echocardiograms were performed approximately ten weeks after the initial assessment visits. Left ventricular measurements were done from two-dimensionally guided M-mode tracings according to the recommendations of the American Society of Echocardiography (18). If an M-mode tracing was technically inadequate, linear measurements were performed from the two-dimensional study (19). Up to six echocardiographic cycles were measured and averaged. Left ventricular mass (LVM) was calculated using the corrected American Society of Echocardiography formula: $0.8 \times(1.04 \times$ [interventricular septum thickness in diastole + left ventricular internal dimension in diastole + posterior wall thickness in diastole $)^{3}$ - left ventricular internal dimension in diastole 3 ) +0.6 . The LVM index (LVMI) was calculated by dividing LVM by the estimated body surface area, calculated from height and weight. The LVMI was also used to identify subjects with $\mathrm{LVH}$, defined as $\mathrm{LVMI} \geq 125 \mathrm{~g} / \mathrm{m}^{2}$ for men and $\geq 110 \mathrm{~g} / \mathrm{m}^{2}$ for women (20).

\section{Measurement of subclinical TOD: Urinary albumin excretion rate}

Microalbuminuria is a marker of high cardiovascular risk and the presence of microalbuminuria is also accompanied by an elevated risk of developing a progressive fall in glomerular filtration rate (GFR) (21). The urinary albumin excretion rate (AER) was assessed by means of the first urine sample of the morning. The AER was performed approximately ten weeks after the initial assessment visits. If the result was outside the normal limits, further determinations were made on 24 hours urine samples. The AER was measured with the immunoturbidimetric method (Mitsubishi Kagaku latron Inc., Tokyo, Japan). Microalbuminuria was defined as an AER of $15-150 \mu \mathrm{g} / \mathrm{min}$, normoalbuminuria $<15$ $\mu \mathrm{g} / \mathrm{min}$, and proteinuria $>150 \mu \mathrm{g} / \mathrm{min}(22)$.

\section{Measurement of subclinical TOD: Carotid-femoral pulse wave velocity}

Current guidelines for the management of hypertension introduce the assessment of arterial stiffness by pulse wave velocity (PWV) as an index of hypertension-related cardiovascular TOD (23). Arterial stiffness was determined by measuring the carotid-femoral PWV, using an automatic waveform analyzer with multi-element tonometry sensors (VP-2000, Colin CO. Ltd., Komaki, Japan). They were placed at the left carotid and the left femoral arteries for the recording of pressure waveforms of these arteries. This automatic waveform analyzer of form determines the upstroke of the wave and the pulse transit time on phase velocity theory (24). The distance that the pulse waves travels from the sensors at the carotid to the femoral artery was obtained based on the height by using the formula. The path lengths from the suprasternal notch to the carotid site and to the femur were obtained from superficial measurements. These measurements were performed approximately ten weeks after the initial assessment visits. Then the carotid-femoral PWV was automatically calculated by equation. The cut-off score of $18 \mathrm{~m} /$ sec was determined as abnormal (25). 
Measurement of subclinical TOD: Carotid intima-media thickness

The carotid intima-media thickness (IMT), as measured by B-mode ultrasound, is a surrogate marker for atherosclerosis and is an independent predictor of stroke and myocardial infarction (26). The carotid IMT was determined from a longitudinal ultrasonographic section through the carotid bulb and primary carotid. These measurements were performed approximately ten weeks after the initial assessment visits. For the examination, the patient was supine, with the neck extended slightly and the head directed away from the side of the examination. Longitudinal two-dimensional images of the carotid arteries were obtained in the anterior, lateral, and posterior planes using a $7.5 \mathrm{MHz}$ probe by two sonographers (Vivid 7; GE, Fairfield, Connecticut, USA) outside the Department of Patient Recruitment. Multiple measurements were taken from the distal $1 \mathrm{~cm}$ of the common carotid artery, from the adjoining carotid bulb, and from the proximal $1 \mathrm{~cm}$ of the internal carotid artery, on both the right and left sides. For each side, the mean values of two images were recorded, and the higher value was used in the analysis. A value $0.9 \mathrm{~mm}$ or higher was considered as abnormal (25).

\section{Statistical analyses}

Results were presented as mean \pm SD. Fisher's exact test and independent-samples $t$-tests were used to compare proportions and means. Paired $t$-tests were used to test for differences in mean levels of the various blood pressure measurements. Pearson's correlations were used to assess the associations between $O B P, A B P$, and HBP measurements with LVMI, AER, PWV, and IMT. To assess the independent predictive utility of the different blood pressure measurements, binary logistic regression models were estimated, including age and blood pressure measurements as primary predictors. Relationships between the different measurements of blood pressure and TOD were analyzed by linear regression with calculation of the coefficient of correlation after checking for a normal distribution using Shapiro-Wilks test. The chi-square test was employed to compare the qualitative variables. Differences between values of coefficient of correlation were compared with Fisher's exact tests. Statistical significance was defined by $\alpha=0.05$, two-tailed. Statistical analyses were performed using SPSS version 13.0 (SPSS, Inc., Chicago, IL USA).

\section{Results}

\section{Baseline characteristics}

Table 1 shows the characteristics of the study population. Ninety-three untreated hypertensive patients (60 men, 65\%) were enrolled in the study. The mean age was $49 \pm 13$ years, and mean body mass index was $24.3 \pm 2.9 \mathrm{~kg} / \mathrm{m}^{2}$. The number of patients with previously diagnosed hypertension was $42(45 \%)$. TOD parameters and average blood pressure values obtained by each measurement method are given also in Table 1.
Table 1. Demographics and values of the patients

\begin{tabular}{|c|c|}
\hline Variables & Value (\%) \\
\hline Sex, men/women, $\mathrm{n}$ & $60 / 33(65 / 35)$ \\
\hline Age, years & $49 \pm 13$ \\
\hline Body mass index, $\mathrm{kg} / \mathrm{m}^{2}$ & $24.3 \pm 2.9$ \\
\hline \multicolumn{2}{|l|}{ Associated conditions } \\
\hline Diabetes mellitus & $6(8)$ \\
\hline Smoking & $17(22)$ \\
\hline Dyslipidemia & $5(6)$ \\
\hline Previous diagnosis of hypertension & $42(45)$ \\
\hline $\begin{array}{l}\text { Family history of premature cardiovascular } \\
\text { disease }\end{array}$ & 32 (34) \\
\hline \multicolumn{2}{|l|}{ Target organ damage } \\
\hline LVMI, left-ventricular mass index, $\mathrm{g} / \mathrm{m}^{2}$ & $81.9 \pm 16.3$ \\
\hline AER, urinary albumin excretion rate, $\mathrm{mg} / \mathrm{g} \mathrm{Cr}$ & $16.7 \pm 15.2$ \\
\hline PWV, carotid-femoral pulse wave velocity, $\mathrm{m} / \mathrm{sec}$ & $14.8 \pm 2.6$ \\
\hline IMT, carotid intima media thickness, mm & $0.7 \pm 0.3$ \\
\hline \multicolumn{2}{|l|}{ Blood pressure } \\
\hline Office SBP/DBP, mm Hg & $142.6 \pm 11.3 / 88.6 \pm 7.4$ \\
\hline Home SBP/DBP, mm Hg & $131.3 \pm 11.4 / 82.1 \pm 8.8$ \\
\hline 24 hour Ambulatory SBP/DBP, mm Hg & $139.4 \pm 11.7 / 90.7 \pm 9.5$ \\
\hline Awake ambulatory SBP/DBP, mm Hg & $142.7 \pm 12.1 / 93.5 \pm 10.0$ \\
\hline Asleep ambulatory SBP/DBP, mm Hg & $126.5 \pm 13.2 / 80.1 \pm 10.2$ \\
\hline $\begin{array}{l}\text { DBP - diastolic blood pressure; SBP - systolic blood pressure. } \\
\text { Data are shown as mean } \pm \text { Standard Deviations (SD) }\end{array}$ & \\
\hline
\end{tabular}

Table 2. Correlation coefficients between mean BP and TOD

\begin{tabular}{|l|l|l|l|l|}
\hline Blood pressure & $\begin{array}{c}\text { LVMI, } \\
\mathbf{g} / \mathbf{m}^{2}\end{array}$ & $\begin{array}{c}\text { AER, } \mathbf{m g} / \mathbf{g} \\
\mathbf{C r}\end{array}$ & $\begin{array}{c}\mathbf{P W V} \\
\mathbf{m} / \mathbf{s e c}\end{array}$ & $\begin{array}{c}\text { IMT, } \\
\mathbf{m m}\end{array}$ \\
\hline Office & & & & \\
\hline SBP/DBP, mm Hg & $0.16 / 0.14$ & $0.16 / 0.07$ & $0.27^{*} /-0.03$ & $0.20 / 0.20$ \\
\hline Home & & & & \\
\hline SBP/DBP, mm Hg & $0.33^{* *} / 0.17$ & $0.25^{*} / 0.10$ & $0.42^{* *} / 0.07$ & $0.26^{*} / 0.11$ \\
\hline Ambulatory & & & & \\
\hline 24 hours & & & & \\
\hline SBP/DBP, mm Hg & $0.42^{* *} / 0.32$ & $0.08 /-0.01$ & $0.26^{*} / 0.13$ & $0.38^{* *} / 0.27$ \\
\hline Awake & & & & \\
\hline SBP/DBP, mm Hg & $0.43 / 0.32$ & $0.05 /-0.03$ & $0.25^{*} / 0.09$ & $0.36^{* *} / 0.23^{*}$ \\
\hline Asleep & & & & \\
\hline SBP/DBP, mm Hg & $0.35^{* *} / 0.27^{*}$ & $0.12 / 0.02$ & $0.21 / 0.17$ & $0.30^{* *} / 0.2^{*}$ \\
\hline DBP - diastolic blood pressure; SBP - systolic blood pressure; ${ }^{*} P<0.05^{* *} P<0.01$ \\
\hline
\end{tabular}

\section{Relationship between mean BP Levels and indices of} subclinical TOD

The correlation coefficients of blood pressure measurement with subclinical TOD are presented in Table 2. The correlation coefficients of LVMI with systolic HBP was $0.33(p<0.05), 24$ hours systolic ABP $0.42(p<0.05)$, and asleep ABP (SBP/DBP) 
Table 3A. Regression analysis for predictors of $L V M I\left[\geq 125 \mathrm{~g} / \mathrm{m}^{2}(\mathrm{M})\right.$ or $\left.\geq 110 \mathrm{~g} / \mathrm{m}^{2}(\mathrm{~W})\right]$ using HBP and other variables

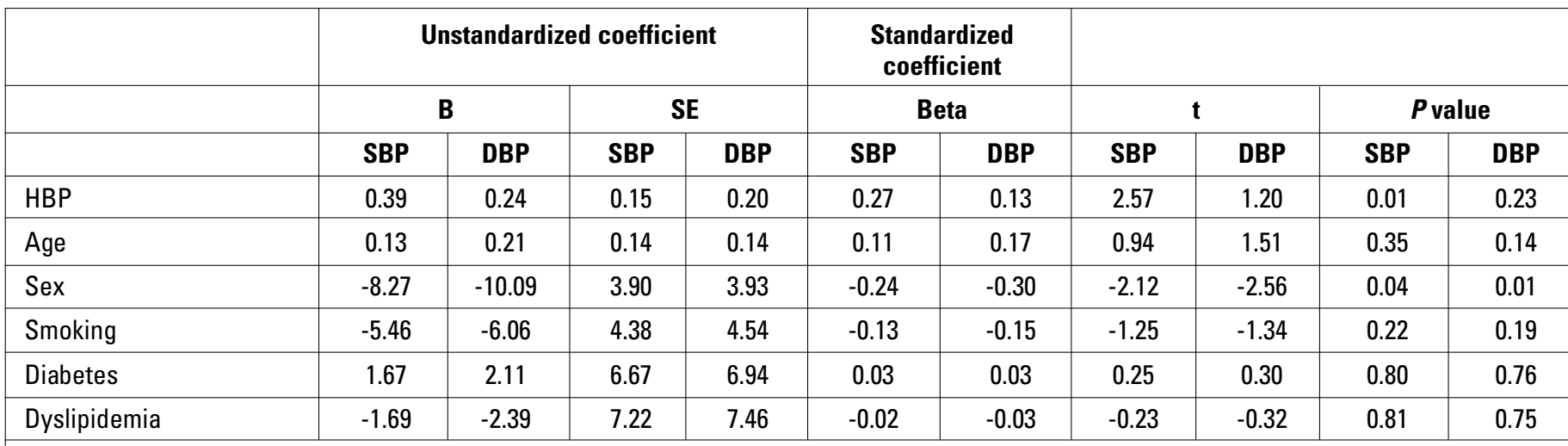

R-square (SBP/DBP)=0.163/0.103; Adjusted R-square (SBP/DBP) =0.112/0.049. Cut-off values of LVMI $\geq 125 \mathrm{~g} / \mathrm{m}^{2}$ (M) and $\geq 110 \mathrm{~g} / \mathrm{m}^{2}$ (W). B-blood; DBP - diastolic blood pressure;

HBP - home blood pressure; SBP - systolic blood pressure

Table 3B. Regression analysis for predictors of LVMI $\left[\geq 125 \mathrm{~g} / \mathrm{m}^{2}(\mathrm{M})\right.$ or $\left.\geq 110 \mathrm{~g} / \mathrm{m}^{2}(\mathrm{~W})\right]$ using ABP and other variables

\begin{tabular}{|c|c|c|c|c|c|c|c|c|c|c|}
\hline & \multicolumn{4}{|c|}{ Unstandardized coefficient } & \multirow{2}{*}{\multicolumn{2}{|c|}{$\begin{array}{c}\begin{array}{c}\text { Standardized } \\
\text { coefficient }\end{array} \\
\text { Beta }\end{array}$}} & & & & \\
\hline & & & & & & & \multicolumn{2}{|c|}{$\mathbf{t}$} & \multicolumn{2}{|c|}{$P$ value } \\
\hline & SBP & DBP & SBP & DBP & SBP & DBP & SBP & DBP & SBP & DBP \\
\hline $\mathrm{ABP}, 24 \mathrm{~h}$ & 0.53 & 0.47 & 0.15 & 0.20 & 0.39 & 0.28 & 3.50 & 2.33 & 0.0007 & 0.02 \\
\hline Age & 0.15 & 0.18 & 0.14 & 0.14 & 0.12 & 0.15 & 1.14 & 1.32 & 0.26 & 0.19 \\
\hline Sex & -4.43 & -6.10 & 4.09 & 4.32 & -0.13 & -0.18 & -1.08 & -1.41 & 0.28 & 0.16 \\
\hline Smoking & -5.79 & -6.31 & 4.25 & 4.42 & -0.14 & -0.15 & -1.36 & -1.43 & 0.18 & 0.16 \\
\hline Diabetes & 2.51 & 3.69 & 6.48 & 6.82 & 0.04 & 0.06 & 0.39 & 0.54 & 0.70 & 0.59 \\
\hline Dyslipidemia & -3.16 & -1.86 & 6.97 & 7.27 & -0.04 & -0.03 & -0.45 & -0.26 & 0.65 & 0.80 \\
\hline
\end{tabular}

$0.35 / 0.27(p<0.05 / 0.01)$. However, the correlation between OBP (SBP/DBP) and LVMI was not statistically significant. Systolic HBP was also correlated with AER $(r=0.25, p<0.05)$. The correlation coefficients of PWV with systolic OBP was $0.27(p<0.05)$, systolic HBP $0.42(p<0.01), 24$ hours systolic ABP $0.26(p<0.05)$, and awake systolic ABP $0.25(p<0.05)$. For IMT, systolic HBP $(r=0.26$, $p<0.05)$, 24 hours systolic $A B P(r=0.38, p<0.01)$, awake $A B P(S B P /$ DBP) $(r=0.36, p<0.01 / r=0.23, p<0.05)$ and asleep ABP (SBP/DBP) $(r=0.30, p<0.01 / r=0.2, p<0.05)$ were significantly correlated. According to the indices of subclinical TOD, it showed the stronger relationship with either the HBP or the ABP than with the OBP.

In order to further confirm, we performed binary logistic regression analysis for individual TOD parameters such as age, sex, smoking, diabetes, dyslipidemia, and all three BP measurements. With cut-off values of $L V M I \geq 125 \mathrm{~g} / \mathrm{m}^{2}(\mathrm{M})$ and $\geq 110$ $\mathrm{g} / \mathrm{m}^{2}(\mathrm{~W})$, the results are as shown in Table 3A. As Table 3B shows, systolic HBP and 24 hours systolic and diastolic ABP were significant predictors of LVMI after adjusting other factors. In the same way, for AER [cut-off values, $\geq 22$ (M) or $\geq 31$ (F) $\mathrm{mg} / \mathrm{g} \mathrm{Cr}$ ] and PWV (cut-off values, $18 \mathrm{~m} / \mathrm{sec}$ ), the results were similar as shown in Tables 4A, B and 5A, B. Systolic HBP and 24 hours systolic and diastolic ABP were statistically significant predictors of $A E R$ and $P W V$, independent of other predictors.

\section{Relationship between BPV and TOD}

Table 6 shows coefficients of correlation between BPV and the indices of subclinical TOD. The correlation coefficients of LVMI with 24 hours systolic ABP variability (ABPV) was 0.25 $(p<0.05)$, and with asleep ABPV (systolic/diastolic ABPV) was $0.30 / 0.24(p<0.01 / p<0.05)$. Systolic home BPV (HBPV) was significantly correlated with PWV $(r=0.30, p<0.01)$ and IMT $(r=0.24$, $\mathrm{p}<0.05$ ). A binary logistic regression analysis for individual TOD parameters showed that systolic HBPV and 24 hours systolic $A B P V$ were significant predictors of LVMI, AER, PWV and IMT (all $p<0.05$ ).

\section{Discussion}

The role of ABP monitoring in the management of hypertension and the prediction of cardiovascular events has been well established (2). Meanwhile, HBP measurements are recognized to share most of the advantages of $\mathrm{ABP}$ monitoring. Recent metaanalysis of the evidence on the ability of HBP to subclinical TOD has been published, and it reported similar correlations of LVH with HBP (coefficients $r=0.46 / 0.28$, systolic/diastolic) as with $A B P$ measurements $(0.37 / 0.26, P=N S$ for difference vs. HBP) (10). However, apart from echocardiographic LVH, the evidence for other indices of subclinical TOD is rather weak and uncertain. 
Her et al.

Table 4A. Regression analysis for predictors of AER $[\geq 22$ (M) or $\geq 31$ (F) $\mathrm{mg} / \mathrm{g} \mathrm{Cr}]$ using HBP and other variables

\begin{tabular}{|c|c|c|c|c|c|c|c|c|c|c|}
\hline & \multicolumn{4}{|c|}{ Unstandardized coefficient } & \multirow{2}{*}{\multicolumn{2}{|c|}{$\begin{array}{c}\begin{array}{c}\text { Standardized } \\
\text { coefficient }\end{array} \\
\text { Beta }\end{array}$}} & & & & \\
\hline & & & & & & & \multicolumn{2}{|c|}{$\mathbf{t}$} & \multicolumn{2}{|c|}{$P$ value } \\
\hline & SBP & DBP & SBP & DBP & SBP & DBP & SBP & DBP & SBP & DBP \\
\hline HBP & 0.41 & 0.35 & 0.13 & 0.17 & 0.31 & 0.20 & 3.17 & 2.00 & 0.002 & 0.049 \\
\hline Age & 0.04 & 0.11 & 0.12 & 0.12 & 0.03 & 0.10 & 0.33 & 0.91 & 0.74 & 0.37 \\
\hline Sex & 11.79 & 10.37 & 3.39 & 3.45 & 0.37 & 0.33 & 3.48 & 3.01 & 0.0008 & 0.004 \\
\hline Smoking & 3.03 & 2.21 & 3.75 & 3.90 & 0.079 & 0.06 & 0.81 & 0.57 & 0.42 & 0.57 \\
\hline Diabetes & 18.08 & 19.11 & 5.73 & 6.00 & 0.30 & 0.32 & 3.16 & 3.19 & 0.0022 & 0.002 \\
\hline Dyslipidemia & 2.57 & 2.36 & 6.20 & 6.44 & 0.04 & 0.04 & 0.41 & 0.37 & 0.68 & 0.71 \\
\hline
\end{tabular}

Table 4B. Regression analysis for predictors of $A E R[\geq 22$ (M) or $\geq 31$ (F) $\mathbf{m g} / \mathrm{g} \mathrm{Cr}]$ using ABP and other variables

\begin{tabular}{|c|c|c|c|c|c|c|c|c|c|c|}
\hline & \multicolumn{4}{|c|}{ Unstandardized coefficient } & \multirow{2}{*}{\multicolumn{2}{|c|}{$\begin{array}{c}\text { Standardized } \\
\text { coefficient }\end{array}$}} & \multirow{2}{*}{\multicolumn{2}{|c|}{ t }} & \multirow{2}{*}{\multicolumn{2}{|c|}{$P$ value }} \\
\hline & \multicolumn{2}{|c|}{ B } & \multicolumn{2}{|c|}{ SE } & & & & & & \\
\hline & SBP & DBP & SBP & DBP & SBP & DBP & SBP & DBP & SBP & DBP \\
\hline$A B P, 24 h$ & 0.34 & 0.38 & 0.14 & 0.18 & 0.26 & 0.24 & 2.46 & 2.11 & 0.02 & 0.04 \\
\hline Age & 0.08 & 0.10 & 0.12 & 0.13 & 0.07 & 0.08 & 0.68 & 0.79 & 0.50 & 0.43 \\
\hline Sex & 13.20 & 13.09 & 3.74 & 3.87 & 0.41 & 0.41 & 3.53 & 3.39 & 0.001 & 0.001 \\
\hline Smoking & 2.80 & 2.33 & 3.84 & 3.89 & 0.07 & 0.06 & 0.73 & 0.60 & 0.47 & 0.55 \\
\hline Diabetes & 18.35 & 19.48 & 5.87 & 6.00 & 0.30 & 0.32 & 3.13 & 3.25 & 0.002 & 0.002 \\
\hline Dyslipidemia & 0.89 & 1.91 & 6.30 & 6.39 & 0.01 & 0.03 & 0.14 & 0.30 & 0.89 & 0.77 \\
\hline
\end{tabular}

Previous study of hypertensive patients in primary care reported significant correlations of systolic HBP and daytime ABP with both LVMI and AER (16). Other study showed that the addition of nighttime HBP to other BP measurements improves the association of $B P$ with hypertensive subclinical TOD such as LVMI and urine AER (13). In common with previous studies, the results of our study showed that ABP and HBP measurements are much more closely related to hypertension related TOD than $\mathrm{OBP}$ measurements.

In particular, HBP measurements showed a consistent relationship with many indices of subclinical TOD such as LVMI, AER, and PWV. Nevertheless systolic HBP needed a relatively small number of measurements, it showed better predictive power than 24 hours ABP for PWV. It might be attributed that HBP measurements are usually taken under more standardized conditions of setting, activity and posture at home after few minutes sitting rest. Also, a consistent finding in this analysis was that systolic HBP was more closely associated with the indices of subclinical TOD than diastolic HBP, which is in line with the previous results on the cardiovascular risk associated with systolic hypertension (27). In short, the outcome of this study may be another objective evidence on the value of HBP measurements in the prediction of hypertension induced TOD.
Furthermore, our study showed high systolic HBPV and 24 hours systolic ABPV have significant correlation with TOD. BPV is the result of complex interaction between external environmental stimuli and cardiovascular control mechanisms (28). BPV has been shown to rise with high levels of blood pressure and be correlated with TOD, independent of absolute blood pressure values (29). Previous studies have shown a direct association between increased 24 hour systolic ABPV and higher incidence of cardiovascular complications in patients with treated hypertension after accounting for the greater risk due to the elevated mean BP levels (30). Also, recent study showed higher ABPV was associated with early depressed LV systolic function in newly diagnosed untreated hypertensive patients (31). Although the importance of BPV as an independent risk factor remains controversial $(32,33)$, our study may be possibly included as one of the prospective pilot studies which handle BPV and TOD in untreated hypertensive.

\section{Study limitations}

Our study has some limitations. First, two OBP measurements were performed during each visit, and $A B P$ monitoring was performed only once. Therefore, we cannot exclude the possibility of different results, if a larger number of OBP mea- 
Table 5A. Regression analysis for predictors of PWV using HBP and other variables

\begin{tabular}{|c|c|c|c|c|c|c|c|c|c|c|}
\hline & \multicolumn{4}{|c|}{ Unstandardized coefficient } & \multirow{2}{*}{\multicolumn{2}{|c|}{$\begin{array}{c}\begin{array}{c}\text { Standardized } \\
\text { coefficient }\end{array} \\
\text { Beta }\end{array}$}} & \multirow{2}{*}{\multicolumn{2}{|c|}{$\mathbf{t}$}} & \multirow{2}{*}{\multicolumn{2}{|c|}{$P$ value }} \\
\hline & \multicolumn{2}{|c|}{ B } & \multicolumn{2}{|c|}{ SE } & & & & & & \\
\hline HBP & 8.15 & 2.40 & 8.15 & 2.87 & 0.35 & 0.08 & 3.77 & 0.84 & 0.001 & 0.41 \\
\hline Age & 8.84 & 10.37 & 8.84 & 2.09 & 0.46 & 0.54 & 4.49 & 4.95 & $<.001$ & $<.001$ \\
\hline Smoking & 60.82 & 60.68 & 60.82 & 73.97 & 0.09 & 0.08 & 0.90 & 0.82 & 0.37 & 0.41 \\
\hline Diabetes & 159.09 & 201.43 & 159.09 & 115.43 & 0.14 & 0.17 & 1.51 & 1.75 & 0.13 & 0.09 \\
\hline Dyslipidemia & -22.99 & -30.95 & -22.99 & 115.04 & -0.02 & -0.03 & -0.22 & -0.27 & 0.83 & 0.79 \\
\hline
\end{tabular}

R-square (SBP/DBP)=0.439/0.336; Adjusted R-square (SBP/DBP)=0.393/0.281. B - blood; DBP - diastolic blood pressure; HBP - home blood pressure; PWV-pulse-wave velocity; SBP -

systolic blood pressure; SE - standard error

Table 5B. Regression analysis for predictors of PWV using ABP and other variables

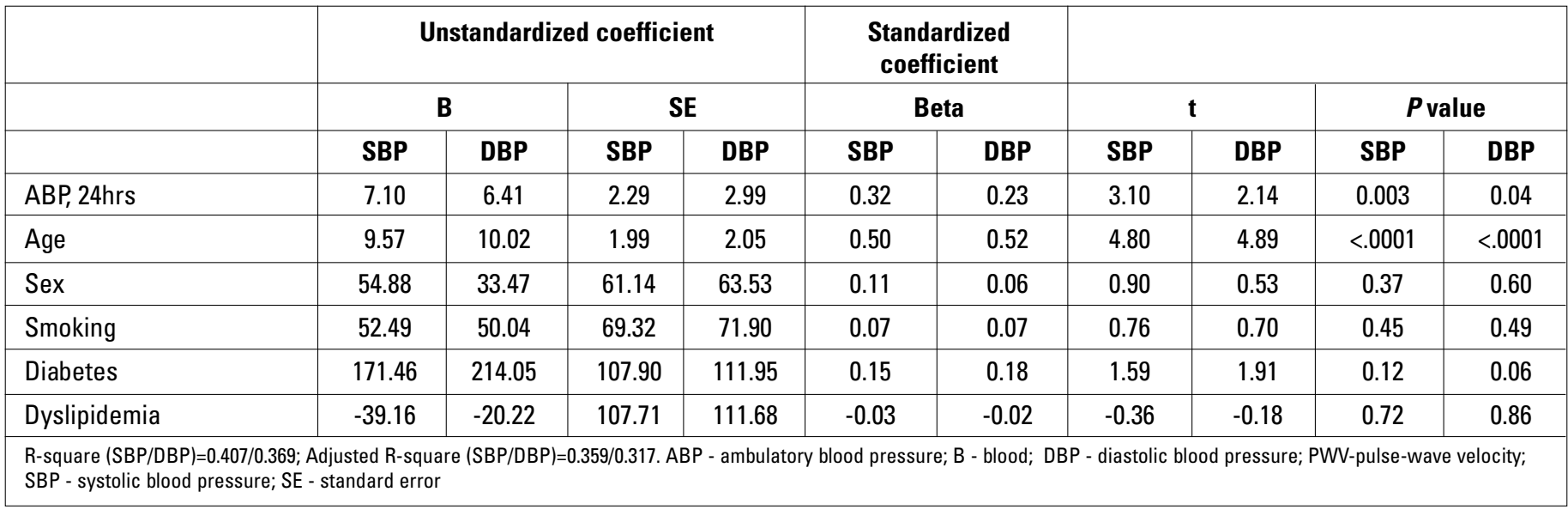

Table 6. Correlation coefficients between BP variability and TOD

\begin{tabular}{|c|c|c|c|c|}
\hline Blood pressure variability & LVMI, $g / m^{2}$ & AER, $\mathrm{mg} / \mathrm{gCr}$ & PWV, m/sec & IMT, mm \\
\hline \multicolumn{5}{|l|}{ Home } \\
\hline Systolic / Diastolic BPV & $0.10 / 0.08$ & $0.15 / 0.01$ & $0.30^{* *} / 0.04$ & $0.24^{*} / 0.10$ \\
\hline \multicolumn{5}{|l|}{ Ambulatory } \\
\hline \multicolumn{5}{|l|}{24 hours } \\
\hline Systolic / Diastolic BPV & $0.25 * / 0.14$ & $0.08 / 0.05$ & $-0.02 /-0.13$ & $0.11 /-0.01$ \\
\hline \multicolumn{5}{|l|}{ Awake } \\
\hline Systolic / Diastolic BPV & $0.18 / 0.08$ & $0.16 / 0.08$ & $-0.01 /-0.11$ & $0.14 / 0.02$ \\
\hline \multicolumn{5}{|l|}{ Asleep } \\
\hline Systolic / Diastolic BPV & $0.30^{* *} / 0.24^{*}$ & $-0.10 / 0.06$ & $0.04 / 0.02$ & $0.02 / 0.08$ \\
\hline
\end{tabular}

surements or ABP monitoring were obtained. Second, our study focused on a limited number of patients. Because of the low values of PWV and the relatively small percentage of patients with LVH and microalbuminuria, the sample size was relatively small. Thus, caution is warranted that our study population might not be representative of the general hypertensive patients in clinical practice. A further study including a larger number of patients with more severe hypertension and longer duration may be needed for more precise conclusions.

\section{Conclusion}

In conclusion, HBP measurements are more closely associated with hypertension related TOD compared with OBP measurements in untreated hypertensive. This study suggests that HBP is as good 
as $\mathrm{ABP}$ monitoring and superior to the conventional OBP measurements in regard to their association with subclinical TOD assessed by LVMI, AER, and PWV. We expect that HBP measurements would give valuable information on the cardiovascular TOD in hypertensive patients in addition to ABP monitoring.

\section{Conflict of interest: None declared.}

\section{Peer-review: Externally peer-reviewed.}

Authorship contributions: Concept - S.J.R.; Design - B.K.L.; Supervision - S.J.R.; Resource - H.M.K.; Materials - P.K.M.; Data collection \&/or processing - Y.H.K.; Analysis \&/or interpretation - A.Y.H.; Literature search - J.Y.K.; Writing - A.Y.H.; Critical review - E.Y.C.; Other - B.K.H.

Acknowledgements: This study was supported by 2013 Research Grant from Kangwon National University.

\section{References}

1. Lewington S, Clarke R, Qizilbash N, Peto R, Colliins R. Age-specific relevance of usual blood pressure to vascular mortality: a metaanalysis of individual data for one million adults in 61 prospective studies. Lancet 2002; 360: 1903-13. [CrossRef]

2. O'Brien E, Asmar R, Beilin L, Imai Y, Mancia G, Mengden T, et al. European Society of Hypertension recommendations for conventional, ambulatory and home blood pressure measurement. J Hypertens 2003; 21: 821-48. [CrossRef]

3. International Society for Chronobiology; American Association of Medical Chronobiology and Chronotherapeutics; Spanish Society of Applied Chronobiology, Chronotherapy, and Vascular Risk; Spanish Society of Atherosclerosis; Romanian Society of Internal Medicine, Hermida RC, Smolensky MH, Ayala DE, Portaluppi F. 2013 ambulatory blood pressure monitoring recommendations for the diagnosis of adult hypertension, assessment of cardiovascular and other hypertension-associated risk, and attainment of therapeutic goals. Chronobiol Int 2013; 30: 355-410. [CrossRef]

4. National Institute for Health and Clinical Excellence. Hypertension: clinical management for primary hypertension in adults. Clinical Guideline 127, 2011. www.nice.org.uk/nicemedia/ live/13561/560071/56007.pdf. Assessed 5 Nov. 2011.

5. Stergiou GS, Baibas NM, Gantzarou AP, Skeva II, Kalkana CB, Roussias LG, et al. Reproducibility of home, ambulatory and clinic blood pressure: implications for the design of trials for the assessment of antihypertensive drug efficacy. Am J Hypertens 2002; 15: 101-4. [CrossRef]

6. Fagard R, Staessen JA, Thijs $L$. The relationship between left ventricular mass and daytime and night-time blood pressures: a meta-analysis of comparative studies. J Hypertens 1995; 13: 823-9. [CrossRef]

7. Mulè G, Caimi G, Cottone S, Nardi E, Andronico G, Piazza G, et al. Value of home blood pressures as predictor of target organ damage in mild arterial hypertension. J Cardiovasc Risk 2002; 9: 123-9. [CrossRef]

8. Staessen JA, Asmar R, De Buyzere M, Imai Y, Parati G, Shimada K, et al. Participants of the 2001 Consensus Conference on Ambulatory Blood Pressure Monitoring. Task Force II: Blood pressure measurement and cardiovascular outcome. Blood Press Monit 2001; 6: 355-70. [CrossRef]
9. Ohkubo T, Imai Y, Tsuji I, Nagai K, Kato J, Kikuchi N, et al. Home blood pressure measurements has a stronger predictive power for mortality than dose screening blood pressure measurement: a population-based observation in Ohasama, Japan. J Hypertens 1998; 16: 971-5. [CrossRef]

10. Bliziotis IA, Destounis A, Stergiou GS. Home versus ambulatory and office blood pressure in predicting target organ damage in hypertension: a systematic review and meta-analysis. J Hypertens 2012; 30: 1289-99. [CrossRef]

11. Martinez MA, Sancho T, Garcia P, Moreno P, Rubio JM, Palau FJ, et al. Home blood pressure in poorly controlled hypertension: relationship with ambulatory pressure and organ damage. Blood Press Monit 2006; 11: 207-13. [CrossRef]

12. Gaborieau V, Delarche N, Gosse P. Ambulatory blood pressure monitoring versus self-measurement of blood pressure at home: correlation with target organ damage. J Hypertens 2008; 26: 1919-27. [CrossRef]

13. Ishikawa J, Hoshide S, Eguchi K, Ishikawa S, Shimada K, Kario K Japan Morning Surge-Home Blood Pressure Study Investigators Group. Night time home blood pressure and the risk of hypertensive target organ damage. Hypertension 2012; 60: 921-8. [CrossRef]

14. Quinn RR, Hemmelgarn BR, Padwal RS, Myers MG, Cloutier L, Bolli P, et al. The 2010 Canadian Hypertension Education Program recommendations for the management of hypertension: part I - blood pressure measurement, diagnosis and assessment of risk. Can $\mathrm{J}$ Cardiol 2010; 26: 241-8. [CrossRef]

15. Parati G. Blood pressure variability: its measurement and significance in hypertension. J Hypertens Suppl 2005; 23: 19-25. [CrossRef]

16. Bilo G, Giglio A, Styczkiewicz K, Caldara G, Kawecka-Jaszcz K, Mancia G, et al. How to improve the assessment of 24-h blood pressure variability. Blood Press Monit 2005; 10: 321-3. [CrossRef]

17. Aqabiti-Rosei E, Muiesan ML, Salvetti M. Evaluation of subclinical target organ damage for risk assessment and treatment in the hypertensive patients: left ventricular hypertrophy. J Am Soc Nephrol 2006; 17: 104-8. [CrossRef]

18. Sahn DJ, DeMaria A, Kisslo J, Weyman A. Recommendations regarding quantitation in M-mode echocardiography: results of a survey of echocardiographic measurements. Circulation 1978; 58: 1072-83. [CrossRef]

19. Schiller NB, Shah PM, Crawford M, DeMaria A, Devererux R, Feigenbaum $\mathrm{H}$, et al. Recommendations for quantitation of the left ventricle by two-dimensional echocardiography. American Society of Echocardiography Committee on Standards, Subcommittee on Quantitation of Two-Dimensional Echocardiograms. J Am Soc Echocardiogr 1989; 2: 358-67. [CrossRef]

20. Alfakih K, Reid S, Hall A, Sivananthan MU. The assessment of left ventricular hypertrophy in hypertension. J Hypertens 2006; 24: 1223-30. [CrossRef]

21. Ruilope $\mathrm{LM}$, Bakris GL. Renal function and target organ damage in hypertension. Eur Heart J 2011; 32: 1599-604. [CrossRef]

22. Mogensen CE, Chachati A, Christensen CK, Close CF, Deckert T, Hommel $E$, et al. Microalbuminuria: an early marker of renal involvement in diabetes. Uremia Invest 1985; 9: 85-95.

23. Milan A, Tosello F, Fabri A, Vairo A, Leone $D$, Chiarlo $M$, et al. Arterial stiffness: from physiology to clinical implications. High Blood Press Cardiovasc Prev 2011; 18: 1-12. [CrossRef]

24. Ueda I, Tagawa T, Watanabe S, Yamakawa K, Yasu T, Ueda S. Comparability and reproducibility of the carotid-femoral pulse wave velocity measurements using a multi-element carotid tonometry sensor. J Hum Hypertens 2008; 22: 699-703. [CrossRef] 
25. Ian G, Dan A, Kunt B, Gudrun B, Gunila B, Renata C, et al. European guidelines on cardiovascular disease prevention in clinical practice: executive summary. Fourth Joint Task Force of the European Society of Cardiology and other societies on cardiovascular disease prevention in clinical practice (constituted by representatives of nine societies and by invited experts) Eur J Cardiovasc Prev Rehabil 2007; 14: 1-40.

26. Cobble M, Bale B. Carotid intima-media thickness: knowledge and application to everyday practice. Postgrad Med 2010; 122: 10-8. [CrossRef]

27. Weber MA, Bakris GL, Hester A, Weir MR, Hua TA, Zappe D, et al. Systolic blood pressure and cardiovascular outcomes during treatment of hypertension. Am J Med 2013; 126: 501-8. [CrossRef]

28. Fratolla A, Parati G, Cuspidi C. Prognostic value of 24 -hour blood pressure variability. J Hypertens 1993; 11: 1133-7. [CrossRef]

29. Mancia G, Parati G, Hennig M, Flatau B, Omboni S, Glavina F, et al. Relation between blood pressure variability and carotid artery damage in hypertension: baseline data from the European
Lacidipine Study on Atherosclereosis (ELSA). J Hypertens 2001; 19: 1981-9. [CrossRef]

30. Sander D, Kukla C, Kingelhofer J. Relationship between circadian blood pressure patterns and progression of early carotid atherosclerosis: A 3-year follow-up study. Circulation 2000; 102: 1536-41. [CrossRef]

31. Tatasciore A, Zimarino M, Tommasi R, Renda G, Schillaci G, Parati G, et al. Increased short-term blood pressure variability is associated with early left ventricular systolic dysfunction in newly diagnosed untreated hypertensive patients. J Hypertens 2013; 31: 1653-61. [CrossRef]

32. Hoshide S, Yano Y, Shimizu M, Eguchi K, Ishikawa J, Kario K. Is home blood pressure variability itself an interventional target beyond lowering mean home blood pressure during anti-hypertensive treatment? Hypertens Res 2012; 35: 862-6. [CrossRef]

33. Parati G, Ochoa JE, Bilo G. Blood pressure variability, cardiovascular risk, and risk for renal disease progression. Curr Hypertens Rep 2012; 14: 421-31. [CrossRef] 